\title{
Hepatocellular Carcinoma and Liver Transplantation: State of the Art
}

\author{
Andrea Mancuso*1,2 and Giovanni Perricone ${ }^{1}$ \\ ${ }^{1}$ Epatologia e Gastroenterologia, Ospedale Niguarda Ca' Granda, Milano, Italy; ${ }^{2}$ Medicina Interna 1, Azienda di Rilievo Nazionale \\ ad Alta Specializzazione Civico - Di Cristina - Benfratelli, Palermo, Italy
}

\begin{abstract}
Hepatocellular carcinoma ( $\mathrm{HCC}$ ) is an aggressive tumor that often occurs in chronic liver disease and cirrhosis. The incidence of $\mathrm{HCC}$ is growing worldwide.

With respect to any other available treatment for liver cancer, liver transplantation (LT) has the highest potential to cure. LTallows for removal at once of both the tumor ("seed") and the damaged-hepatic tissue ("soil") where cancerogenesis and chronic liver disorders have progressed together. The Milan criteria (MC) have been applied worldwide to select patients with HCC for LT, yielding a 4-year survival rate of $75 \%$. These criteria represent the benchmark for patient selection and are the basis for comparison with any other suggested criteria.

However, MC are often considered to be too restrictive, and recent data show that between $25 \%$ and $50 \%$ of patients with $\mathrm{HCC}$ are currently transplanted beyond conventional indications. Consequently, any unrestricted expansion of selection criteria will increase the need for donor organs, lengthen waiting periods, increase drop-out rates, and impair outcomes on intention-to-treat analysis. Management of HCC recurrence after LT is challenging. There are a few reports available regarding the safety and efficacy of sorafenib for $\mathrm{HCC}$ recurrence after $\mathrm{LT}$, but the data are heterogeneous. A multi-center prospective randomized controlled trial comparing placebo with sorafenib is advised. Alternatively, a metaanalysis of patient survival with sorafenib for HCC recurrence after LT could be helpful to characterize the therapeutic benefit and safety of sorafenib.

Here, we review the use of LT for HCC, with particular emphasis on the selection criteria for transplantation in patients with HCC and management of HCC recurrence after LT.
\end{abstract}

Keywords: Hepatocellular carcinoma; Liver transplantation; Selection criteria; Milan criteria; Recurrence; Sorafenib.

Abbreviations: AAIR, age-adjusted incidence rate; EASL-EORTC, European Association for the Study of the Liver - European Organisation for Research and Treatment of Cancer; ELTR, European Liver Transplant Registry; HAART, highly active anti-retroviral therapy; HBV, hepatitis B virus; HCC, hepatocellular carcinoma; HCV, hepatitis C virus; HIV, human immunodeficiency virus; ITT, intention-to-treat; LDLT, living donor liver transplantation; LT, liver transplantation; MC, Milan criteria; NASH, non-alcoholic steatohepatitis; OPTN, organ procurement and transplantation network; RFA, radio-frequency ablation; RFTA, radio-frequency thermal ablation; TACE, trans-arterial chemoembolization; UNOS, United Network for Organ Sharing; UCSF, University of San Francisco. Received: 23 April 2014; Revised: 30 June 2014; Accepted: 01 July 2014

DOI: $10.14218 /$ JCTH.2014.00013.

*Correspondence to: Andrea Mancuso, Medicina Interna 1, A.R.N.A.S. Civico, Piazzale Liotti 4, Palermo 90100, Italy. Tel: +39-329-899-7893, Fax: +39-091-609-0252, E-mail: mancandrea@libero.it
(C) 2014 The Second Affiliated Hospital of Chongqing Medical University. Published by XIA \& HE Publishing Ltd. All rights reserved.

\section{Introduction}

Liver cancer is the second most common cause of death from cancer worldwide, estimated to be responsible for nearly 746,000 deaths in 2012 ( $9.1 \%$ of the total). The prognosis for liver cancer is very poor, with an overall ratio of mortality to incidence of 0.95 , and the geographical patterns in incidence and mortality are similar (see Table 1 ). ${ }^{1}$

HCC represents more than $90 \%$ of primary liver cancers and is a major global health problem. The incidence of HCC increases progressively with advancing age in all populations, reaching a peak at 70 years. ${ }^{2}$ HCC has a strong male preponderance, with a male to female ratio estimated to be 2.4. ${ }^{1}$ The pattern of HCC occurrence has a clear geographical distribution. ${ }^{1,3}$ In $2012,83 \%$ of the estimated 782,000 new cancer cases worldwide occurred in less developed regions. ${ }^{1}$ The incidence of HCC is growing worldwide.

A variety of important risk factors for the development of HCC have been identified. These include chronic hepatitis $B$ virus (HBV) infection, chronic hepatitis $C$ virus (HCV) infection, alcohol intake, hereditary hemochromatosis, aflatoxin exposure, and cirrhosis of almost any cause. However, HCC can also occur in patients without known risk factors. Approximately $90 \%$ of HCC are associated with a known underlying risk factor (see Table 2). Cirrhosis may be caused by chronic viral hepatitis, alcohol, inherited metabolic diseases such as hemochromatosis or alpha-1-antitrypsin deficiency or Wilson's disease, non-alcoholic fatty liver disease, autoimmune hepatitis, and Budd-Chiari syndrome. All etiologic forms of cirrhosis may be complicated by tumor formation, but the risk is higher in patients with hepatitis infection. Overall, one-third of cirrhotic patients will develop HCC during their lifetime. ${ }^{3-7}$ Rarely, HCC can develop in the absence of cirrhosis.

Overall, the incidence of HCC is increasing not only in the general population of patients with cirrhosis, but also in some subgroups of patients, like those with human immunodeficiency virus (HIV) infection or thalassemia. In fact, significant improvement in outcomes due to iron chelating drugs in thalassaemic patients and to highly active anti-retroviral therapy (HAART) in HIV patients has recently revealed HCC as a main complication of the underlying hepatic disease. ${ }^{8-13}$

Liver transplantation (LT) is an established treatment for HCC. ${ }^{14,15}$ If donor graft supply was unlimited, every cirrhotic patient with HCC would be offered LTas the optimal treatment 
Mancuso A. et al: Hepatocellular carcinoma and liver transplantation: State of the art

Table 1. Liver cancer. Estimated incidence, mortality, and 5-year prevalence worldwide in 2012

\begin{tabular}{|c|c|c|c|c|c|c|c|c|c|}
\hline \multirow{2}{*}{$\begin{array}{l}\text { Estimated } \\
\text { numbers } \\
\text { (thousands) }\end{array}$} & \multicolumn{3}{|c|}{ Men } & \multicolumn{3}{|c|}{ Women } & \multicolumn{3}{|c|}{ Both sexes } \\
\hline & Cases & Deaths & $5-y r$ prev & Cases & Deaths & 5-yr prev & Cases & Deaths & $5-y r$ prev \\
\hline World & 554 & 521 & 453 & 228 & 224 & 180 & 782 & 746 & 633 \\
\hline $\begin{array}{l}\text { More developed } \\
\text { regions }\end{array}$ & 92 & 80 & 112 & 42 & 43 & 51 & 134 & 123 & 164 \\
\hline $\begin{array}{l}\text { Less developed } \\
\text { regions }\end{array}$ & 462 & 441 & 341 & 186 & 182 & 129 & 648 & 622 & 469 \\
\hline USA & 23 & 17 & 21 & 8 & 7 & 7 & 30 & 24 & 27 \\
\hline China & 293 & 282 & 220 & 101 & 101 & 71 & 395 & 383 & 291 \\
\hline India & 17 & 17 & 8 & 10 & 10 & 5 & 27 & 27 & 13 \\
\hline European Union & 36 & 32 & 33 & 16 & 17 & 14 & 52 & 48 & 47 \\
\hline
\end{tabular}

Source: Globoscan 2012

for their disease. Relative to any other available treatment for liver cancer, LT has the highest potential to cure ${ }^{4,6}$ because of its ability to remove at once both the seeded-HCC and the damaged-hepatic tissue where cancerogenesis and chronic liver disorders have together progressed. ${ }^{16}$

The criteria for determining whether a HCC patient is eligible, upfront, for LT are very heterogeneous and relatively ill-defined. Another controversy is how to manage HCC recurrence after $\mathrm{LT}$ because there is little evidence available regarding improvement of survival with any treatment after LT.

Here, we present a state-of-the-art review on LT for HCC. In particular, this review concentrates on two topics, respectively, selection criteria for LT in patients with HCC and management of HCC recurrence after LT.

\section{Selection criteria for liver transplantation in patients with hepatocellular carcinoma: Milan criteria or expanded criteria?}

The number of LTs for HCC has increased worldwide; and currently in Europe, about $27 \%$ of all LT patients have HCC. ${ }^{18}$
More specifically, in some Mediterranean areas of France, Italy, and Spain, LT for HCC represents more than $40 \%$ of transplants. Over the last decade in Western countries, HCC has had the highest growth increment of all indications for LT. $^{17,18}$ This trend is even more pronounced in Eastern countries, where HCC, in some instances, has equalized or even overtaken cirrhosis as the leading indication for LT. ${ }^{19}$

The broad selection criteria applied two decades ago led to poor results in terms of recurrence ( $32-54 \%$ at 5 years) and survival (5-year survival $<40 \%$ ), but allowed for the identification of the best candidates for this procedure. $6,20,21$ Since the initial results of LT for HCC were negative, likely because LT was initially reserved for advanced HCC not suitable for resection, the reliability of the procedure was questioned. In 1996 , the publication of a pivotal prospective study on 48 patients transplanted for HCC under predefined criteria (single $\mathrm{HCC} \leqslant 5 \mathrm{~cm}$ or $3 \mathrm{HCC} \leqslant 3 \mathrm{~cm}$ each), the so called "Milan criteria" (MC), showed a 4 year survival of $75 \% .^{22}$ Successively, some pioneering groups selecting "optimal candidates" reported 70\% 5-year survival with a recurrence rate below $15 \% .{ }^{23-26}$ Due to these data, LT is now considered to be the first-line treatment for patients with single HCC

Table 2. Geographical distribution of main risk factors for HCC worldwide

\begin{tabular}{|c|c|c|c|c|c|}
\hline Geographic area & AAIR M/F & Risk factors HCV (\%) & HBV (\%) & Alcohol (\%) & Others (\%) \\
\hline Europe & $6.7 / 2.3$ & $60-70$ & $10-15$ & 20 & 10 \\
\hline Southern & $10.5 / 3.3$ & & & & \\
\hline Northern & $4.1 / 1.8$ & & & & \\
\hline North America & $6.8 / 2.3$ & $50-60$ & 20 & 20 & $\begin{array}{l}10 \\
\text { (NASH) }\end{array}$ \\
\hline Asia and Africa & & 20 & 70 & 10 & $\begin{array}{l}10 \\
\text { (Aflatoxin) }\end{array}$ \\
\hline Asia & $21.6 / 8.2$ & & & & \\
\hline China & 23/9.6 & & & & \\
\hline Japan & $20.5 / 7.8$ & 70 & $10-20$ & 10 & 10 \\
\hline Africa & $1.6 / 5.3$ & & & & \\
\hline World & $16 / 6$ & 31 & 54 & 15 & \\
\hline
\end{tabular}

AAIR, Age-adjusted incidence rate; HBV, Hepatitis B virus; $\mathrm{HCV}$, Hepatitis C virus.

Updated from Llovet et. al. according to IARC ${ }^{1}$ 
Table 3. Recommendations on liver transplantation for hepatocellular carcinoma based on the level of evidence and the strength of the data (classification of evidence adapted from National Cancer Institute) and the strength of recommendations following previously reported systems (GRADE systems), according to EASL-EORTC clinical practice guidelines on the management of $\mathrm{HCC}^{6}$

\begin{tabular}{lll}
\hline & $\begin{array}{l}\text { Levels of } \\
\text { evidence* }\end{array}$ & $\begin{array}{l}\text { Grade of } \\
\text { recommendation }\end{array}$ \\
\hline LT Milano IN & $2 \mathrm{~A}$ & $1 \mathrm{~A}$ \\
LDLT & $2 \mathrm{~A}$ & $2 \mathrm{~B}$ \\
LT extended & $2 \mathrm{~B}$ & $2 \mathrm{~B}$ \\
Down-staging & $2 \mathrm{D}$ & $2 \mathrm{C}$ \\
\hline
\end{tabular}

*Adapted from National Cancer Institute

'GRADE system

LT, Liver transplantation; LDLT, Living donor liver transplantation.

$\leqslant 5 \mathrm{~cm}$ or $3 \mathrm{HCC} \leqslant 3 \mathrm{~cm}$ each (see Table 3 ). ${ }^{4-6}$ All publication to date use the strict guidelines set by the MC when considering LT for treatment of $\mathrm{HCC} .{ }^{4-6} \mathrm{~A}$ meta-analysis has confirmed the strong association of MC with a survival advantage (HR 1.7) and with a low risk of selecting an aggressive biologic behavior with respect to patients exceeding them. In fact, $\mathrm{G} 3$ tumors and microvascular invasion are less frequent when MC are met, with a HR of 4.8 and 2.5, respectively. ${ }^{27}$

According to European (ELTR) and American (OPTN) registries, the overall 5-year survival of patients transplanted within the MC $(65-78 \%)$ is similar to non-HCC indications $(65-87 \%){ }^{27-29}$ As a consequence of their success, the MC have been integrated in the BCLC staging system ${ }^{30,31}$ and in the United Network for Organ Sharing (UNOS) pre-transplant staging for organ allocation in the US, ${ }^{32}$ and remain the benchmark for any other prognostic criteria proposed for expanding the indication for LT in cirrhotic patients with HCC. ${ }^{33}$

The need to obtain the optimal benefit from the limited number of organs that are available has prompted the maintenance of strict selection criteria so as to list only those patients with early HCC who have the highest likelihood of survival after transplant. However, this means that some patients with slightly more advanced HCC in whom transplant would offer an acceptable, but not excellent outcome, are excluded from the procedure. ${ }^{34-36}$

Nevertheless, MC are often considered to be too restrictive and a plethora of "expanded criteria" have been suggested. In summary, in order to establish a new policy allowing for expansion of criteria for transplantation, it is essential to develop robust data for the specific category of patients included in the proposed expansion. Novel criteria might have a major impact on all transplant programs and the data needed to support any change should be impeccable. In addition, the impact of the expansion on non-HCC patients waiting for LT should be taken into account. ${ }^{3}$

None of these expanded criteria have been prospectively and independently validated. The partial exceptions are the University of San Francisco (UCSF) criteria (single tumor $\leqslant 6.5 \mathrm{~cm}$ or multiple $\mathrm{HCC} \leqslant 3$ nodules $\leqslant 4.5 \mathrm{~cm}$, with the total tumor diameter $\leqslant 8 \mathrm{~cm}$ ). Notably, there is a significant overlap between patients meeting the Milan and the UCSF criteria, resulting in a modest expansion of the exact number of HCC patients eligible for LT (estimated to be $5-10 \%) .{ }^{37}$ In fact, UCSF criteria on explant identified retrospectively a cohort of patients whose survival was not significantly different from those of patients transplanted for HCC inside the MC. ${ }^{38}$ The same results have been demonstrated by other retrospective experiences from other centers using UCSF criteria. Moreover, a recent prospective study showed a 5 year survival not significantly different in patients transplanted for HCC inside Milan and UCSF criteria. ${ }^{39}$

Today, expansion to UCSF criteria has already been challenged from the pathological point of view by the up-toseven criteria (i.e. those HCC having the number 7 as the sum of the size of the largest tumor and the number of tumors). ${ }^{36}$ In a multicenter retrospective study on over 1,700 explants, the authors demonstrated that HCC inside the "up-to-seven" criteria at explant and without microvascular invasion had a 5 year survival not significantly different from those inside the MC, while survival was significantly worst in cases of HCC inside the "up-to-seven" criteria and with microvascular invasion. ${ }^{36}$ This pathology-based proposal has been recently validated in an independent series, ${ }^{40}$ but the findings must be further validated with prospective studies and is not suitable clinical practice.

The major concerns about the expansion proposals are the lack of specific data on overall survival and drop-out rate on the waiting list for the patients outside the current criteria but fulfilling the expanded criteria. Other recent studies challenging the Milan criteria have proposed different algorithms to optimize patient selection. Nonetheless, 5-year outcome prediction could vary from $70 \%$ to $40 \%$ depending on the presence of microvascular invasion. Thus, preoperative markers of vascular invasion would be required prior to adopting these criteria. ${ }^{6}$

Presently, it is likely that a modest expansion of the number of potential candidates may be considered for validated criteria (such as the up-to-seven criteria that largely include the UCSF criteria), which demonstrate comparable survival for patients outside the MC (see Table 3). ${ }^{6,16}$ As repeatedly noted in scientific and regulatory contexts, any unrestricted expansion of selection criteria will increase the need for donor organs, lengthen waiting periods, increase drop-out rates, and impair outcomes on intention-to-treat (ITT) analyses.

In the present context, the term "down-staging" defines the reduction of the intra-hepatic $\mathrm{HCC}$ burden to meet acceptable criteria for $\mathrm{LT}_{\text {, }}{ }^{11}$ "acceptable" criteria being driven by good expected survival after LT. ${ }^{42}$ This equates to a 5 -year survival comparable to that of HCC patients who meet transplant criteria without requiring down-staging. ${ }^{33}$ Namely, the principle of down-staging is to select a more favorable tumor biology, as determined by response to treatment in the perspective of positive post-LT outcome. ${ }^{41}$ From the seminal experience of the UCSF group, most of the published reports have used the MC as the endpoint for downstaging. In doing so, for a minimal observation period of 3 months (suggested to confirm a sustained response to treatment), a comparable or only slightly reduced survival than that achieved with HCC meeting MC before LT has been reported. 41

According to recommendations, either MC or a modest expansion can be targeted in elective LT for HCC, while for down-staging only conversions to conventional MC are acceptable. ${ }^{33}$ Trans-arterial chemoembolization (TACE) is the single treatment modality most often applied to HCC down-staging, followed by radiofrequency ablation (RFA), radioembolization, and surgical resection. ${ }^{43-48}$ In the 
Mancuso A. et al: Hepatocellular carcinoma and liver transplantation: State of the art

large majority of centers, the choice of treatment - either alone or in combination - is made within multidisciplinary transplant-tumor boards. ${ }^{49}$ Although a treatment strategy based on the individual components of patients/tumors is largely justified, it raises concerns of selection bias when a comparison among treatment strategies is attempted. The same applies to the criteria of exclusion from down-staging procedures, which remain largely undescribed. ${ }^{16}$

Considering the current data, down-staging of patients beyond MC cannot be adopted as a tool to refine patient selection and further research is required (see Table 3 ). ${ }^{6}$ This research should be based on the principle that 5-year survival outcomes of patients undergoing transplantation after successful down-staging should be similar to those of patients transplanted following MC. The EASL-EORTC panel considers, though, that a special policy should be adopted for patients already on the waiting list for LT with tumors progressing beyond MC and liver only disease. In this special circumstance, it is recommended to place the candidate on hold until down-staging by local ablation or chemoembolization is achieved and maintained for at least 3 months. ${ }^{6}$

In summary, guidelines still indicate LT only to HCC inside MC. ${ }^{4-6}$ However, as published experiences show, many centers perform LT outside the MC, using criteria that are different from center to center. Recent data show that even in large areas, between $25 \%$ and $50 \%$ of patients with HCC are currently transplanted beyond conventional indications. ${ }^{33,36,38,39,50-54}$ As a results, any unrestricted expansion of selection criteria will increase the need for donor organs, resulting in lengthened waiting periods, increased drop-out rates, and impaired outcomes in ITT analyses. Extreme deviations from efficiency and equity endpoints should be avoided in criteria expansion.

Whatever the criteria adopted, a significant problem of HCC candidates for LT is drop-out, patients who do not reach the goal of LT because of progression of HCC or causes unrelated to HCC. Many studies have investigated the risks for drop-out, despite its difficulty to define, and these factors include tumor multinodularity, neoadjuvant treatment failures, and elevated AFP or MELD. From an opposing point of view, given the organ shortage, some patients with single $\mathrm{HCC}<2 \mathrm{~cm}$ may benefit from alternative treatments and should avoid LT unless recurrence occurs, highlighting the possibility of salvage transplantation in the low risk population.

Living donor liver transplantation (LDLT), where the right hepatic lobe of a healthy donor is used, has emerged as an alternative to deceased LT. ${ }^{55-56}$ In 2000, there was great enthusiasm for LDLT, and it was estimated that it would represent a significant proportion of the patients transplanted with HCC. ${ }^{57}$ Unfortunately, the associated risks of death (estimated in $0.3 \%$ ) and life-threatening complications (2\%) for the healthy donor have diminished the interest of the transplant community. ${ }^{58,59,60}$ Due to the complexity of the procedure, LDLT must be restricted to centers of excellence in hepatic surgery and transplantation.

Outcome results with LDLT compared with deceased LT have been controversial. Although some studies suggested that LDLT was associated with higher risk of recurrence, these data have not been confirmed. ${ }^{61,62}$ Cost-effectiveness studies suggested that LDLT can be offered to patients with HCC if the waiting list exceeds 7 months, ${ }^{63}$ a policy adopted by the panel of EASL-EORTC. ${ }^{6}$
Hepatocellular carcinoma recurrence after liver transplantation: the need of treatment despite no evidence of survival benefit

Management of HCC recurrence after LT is complex and challenging. Despite the metastatic nature of such a recurrence, treatments resemble those used for HCC in cirrhosis, although there is no evidence that such treatments could improve survival of patients with HCC recurrence after LT.

Approachable localized HCC recurrence should undergo surgery, with indication resembling those of HCC in cirrhosis. Recurrences not suitable for surgery should be treated with RFTA or TACE. However, both surgery and other treatments are empirical, as no evidence of survival benefit exists.

Sorafenib is the treatment of choice for advanced HCC, since survival in sorafenib patients with underlying liver cirrhosis is longer than placebo control. ${ }^{64,65}$ Theoretically, such a systemic therapy could be the best approach for HCC recurrence after LT. However, different observational studies of patients treated with sorafenib for HCC recurrence after LT have reported contradictory results regarding safety and efficacy. In fact, while some authors emphasize the effectiveness and safety of sorafenib, pushing for the general acceptance of the treatment for HCC recurrence after LT, others had safety concerns. ${ }^{66-84}$ In particular, one group reported grade 3-4 adverse events in $92 \%$ of 13 patients, resulting in sorafenib discontinuation in $77 \% .{ }^{72}$ Another study of 11 consecutive patients described a high rate of intolerance or side-effects, causing drug discontinuation in $36 \% .^{70}$ Moreover, some patients in another study died because of massive gastrointestinal bleeding, possibly due to an interaction between everolimus and sorafenib that could facilitate gastrointestinal bleeding. ${ }^{69,75,85}$ In fact, a concern for the concomitant use of sorafenib and HAARTs in HIV has also been reported. ${ }^{86}$

Taken all together, the experiences on treatment with sorafenib for HCC recurrence after LT are too heterogeneous to draw a definite conclusion and further studies are needed. It is advisable that the effort of a multi-center prospective randomized controlled sorafenib versus placebo trial should be made to address this controversial topic. Alternatively, a meta-analysis of survival of patients treated with sorafenib for HCC recurrence after LT could help to identify possible solutions.

\section{Conclusions}

LT has the highest potential cure rate for HCC relative to other options, but the proportion of individuals with HCC on the waiting list for transplant is growing. The MC are the benchmark for patient selection and the basis for comparison with any other suggested criteria. Expansion of criteria is not a widely recommended strategy, since there is a lack of relevant evidence. Any expansion should avoid the saturation of the listing system and poor long-term outcomes after LT. Any unrestricted expansion of selection criteria will increase the need for donor organs, resulting in lengthened waiting periods, increased drop-out rates, and impaired outcomes in ITT analyses. Extreme deviations from efficiency and equity endpoints should be avoided in criteria expansion. "Downstaging" is the reduction of the intra-hepatic HCC burden to meet acceptable criteria for LT. The principle of the strategy is to select individuals whose tumors have a more favorable biology, as determined by treatment response in the 
perspective of positive post-LT outcome. However, treatment may not necessarily change the outcome of LT. Overall, downstaging is weakly recommended as a LT selection tool, unless it is applied in prospective studies with survival and diseaseprogression endpoints.

\section{Conflict of interest}

None

\section{Author contributions}

Writing the review (AM, GP).

\section{References}

[1] IARC; <http://www-dep.iarc.fr/>; 2012.

[2] El-Serag HB, Mason AC. Rising incidence of hepatocellular carcinoma in the United States. N Engl J Med 1999;340:745-750. doi: 10.1056/ NEJM199903113401001.

[3] Parkin DM, Bray F, Ferlay J, Pisani P. Global cancer statistics, 2002. CA Cancer ] Clin 2005:55:74-108 doi: $10.3322 /$ canjclin. 55.2 .74

[4] Bruix J, Sherman M; American Association for the Study of Liver Diseases. Management of Hepatocellular Carcinoma: An Update. Hepatology 2011;53: 1020-1222. doi: 10.1002/hep.24199.

[5] Kudo M, Izumi N, Kokudo N, Matsui O, Sakamoto M, Nakashima O, et al. Management of Hepatocellular Carcinoma in Japan: Consensus-Based Clinical Practice Guidelines Proposed by the Japan Society of Hepatology (JSH) 2010 Updated Version. Dig Dis 2011;29:339-364. doi: 10.1159/ 000327577.

[6] European Association For The Study Of The Liver; European Organisation For Research And Treatment Of Cancer. EASL-EORTC Clinical Practice Guidelines: Management of Hepatocellular Carcinoma. J Hepatol 2012;56:908-943.

[7] Sangiovanni A, Prati GM, Fasani P, Ronchi G, Romeo R, Manini M, et al. The natural history of compensated cirrhosis due to hepatitis $C$ virus: a 17-year cohort study of 214 patients. Hepatology 2006;43:1303-1310. doi: 10.1002/hep. 21176

[8] Ioannou GN, Bryson CL, Weiss NS, Miller R, Scott JD, Boyko EJ. The prevalence of cirrhosis and hepatocellular carcinoma in patients with human immunodeficiency virus infection. Hepatology 2013;57:249-257. doi: 10.1002/hep. 25800 .

[9] Sahasrabuddhe VV, Shiels MS, McGlynn KA, Engels EA. The risk of hepatocellular carcinoma among individuals with acquired immunodeficiency syndrome in the United States. Cancer 2012;118:6226-6233. doi: 10.1002/ cncr. 27694.

[10] Merchante N, Merino E, López-Aldeguer J, Jover F, Delgado-Fernández M, Galindo MJ, et al. Increasing incidence of hepatocellular carcinoma in HIVinfected patients in Spain. Clin Infect Dis 2013;56:143-150. doi: 10.1093/ $\mathrm{cid} / \mathrm{cis} 777$.

[11] Mancuso A, Rigano P, Renda D, Di Salvo V, Pignatti CB, Guddo F, et al. Hepatocellular carcinoma on cirrhosis-free liver in a HCV-infected thalassemic. Am J Hematol 2005;78:158-159. doi: 10.1002/ajh.20289

[12] Mancuso A, Sciarrino E, Renda MC, Maggio A. A prospective study of hepatocellular carcinoma incidence in thalassemia. Hemoglobin 2006;30: 119-124. doi: 10.1080/03630260500455565

[13] Mancuso A. Hepatocellular carcinoma in thalassemia: A critical review. World J Hepatol 2010;2:171-174.

[14] Forner A, Llovet JM, Bruix J. Hepatocellular carcinoma. Lancet 2012;379: 1245-1255. doi: 10.1016/S0140-6736(11)61347-0.

[15] Mazzaferro V, Chun YS, Poon RT, Schwartz ME, Yao FY, Marsh JW, et al. Liver transplantation for hepatocellular carcinoma. Ann Surg Oncol 2008;15: 1001-1007. doi: 10.1245/s10434-007-9559-5.

[16] Mazzaferro V. Selection criteria for HCC and downstaging procedures. In EASL postgraduate course. Transplantation \& the liver. EASL international liver congress, 2013.

[17] Adam R, Karam V, Delvart V, O'Grady J, Mirza D, Klempnauer J, et al. Evolution of indications and results of liver transplantation in Europe. $A$ report from the European Liver Transplant Registry (ELTR). J Hepatol 2012; 57:675-688. doi: 10.1016/j.jhep.2012.04.015.

[18] OPTN/SRTR. Annual Report; 2011.

[19] China Liver Transplant Registry. 2012. http://www.ilts.org/uploads/4 wang.pdf.

[20] Iwatsuki S, Starzl TE, Sheahan DG, Yokoyama I, Demetris AJ, Todo S, et al. Hepatic resection versus transplantation for hepatocellular carcinoma. Ann Surg 1991;214:221-228. doi: 10.1097/00000658-199109000-00005.
[21] Iwatsuki S, Esquivel CO, Gordon RD, Shaw Jr BW, Starzl TE, Shade RR, et al. Liver transplantation for fulminant hepatic failure. Semin Liver Dis $1985 ; 5$ : 325-328. doi: 10.1055/s-2008-1040628.

[22] Mazzaferro V, Regalia E, Doci R, Andreola S, Pulvirenti A, Bozzetti F, et al. Liver transplantation for the treatment of small hepatocellular carcinomas in patients with cirrhosis. N Engl J Med 1996;334:693-699.

[23] Llovet JM, Fuster J, Bruix J. Intention-to-treat analysis of surgical treatment for early hepatocellular carcinoma: resection versus transplantation. Hepatology 1999;30:1434-1440. doi: 10.1002/hep.510300629.

[24] Bismuth H, Majno PE, Adam R. Liver transplantation for hepatocellular carcinoma. Semin Liver Dis 1999;19:311-322. doi: 10.1055/s-2007-1007120.

[25] Bismuth $H$, Chiche L, Adam R, Castaing D, Diamond T, Dennison A. Liver resection versus transplantation for hepatocellular carcinoma in cirrhosis. Ann Surg 1993;218:145-151. doi: 10.1097/00000658-199308000-00005.

[26] Jonas S, Bechstein WO, Steinmüller T, Herrmann M, Radke C, Berg T, et al. Vascular invasion and histopathologic grading determine outcome after liver transplantation for hepatocellular carcinoma in cirrhosis. Hepatology 2001; 33:1080-1086. doi: 10.1053/jhep.2001.23561.

[27] Mazzaferro V, Bhoori S, Sposito C, Bongini M, Langer M, Miceli R, et al. Milan criteria in liver transplantation for hepatocellular carcinoma: an evidencebased analysis of 15 years of experience. Liver Transpl 2011;17 (Suppl 2): S44-57. doi: 10.1002/It.22365.

[28] www.eltr.org/, accessed Nov 2011.

[29] http://www.ustransplant.org/annual reports/current/, accessed Nov 2011.

[30] Llovet JM, Brú C, Bruix J. Prognosis of hepatocellular carcinoma: the BCLC staging classification. Semin Liver Dis 1999;19:329-338. doi: 10.1055/s2007-1007122.

[31] Llovet JM, Di Bisceglie AM, Bruix J, Kramer BS, Lencioni R, Zhu AX, et al. Design and endpoints of clinical trials in hepatocellular carcinoma. J Natl Cancer Inst 2008;100:698-711. doi: 10.1093/jnci/djn134.

[32] Freeman Jr RB, Wiesner RH, Harper A, McDiarmid SV, Lake J, Edwards E, et al. UNOS/OPTN Liver Disease Severity Score, UNOS/OPTN Liver and Intestine, and UNOS/OPTN Pediatric Transplantation Committees. The new liver allocation system: moving toward evidence-based transplantation policy. Liver Transpl 2002;8:851-858. doi: 10.1053/jlts.2002.35927.

[33] Clavien PA, Lesurtel M, Bossuyt PM, Gores G], Langer B, Perrier A, et al. Recommendations for liver transplantation for hepatocellular carcinoma: an international consensus conference report. Lancet Oncol 2012;13:e11-22. doi: 10.1016/S1470-2045(11)70175-9.

[34] Marsh JW, Dvorchik I, Bonham CA, Iwatsuki S. Is the pathologic TNM staging system for patients with hepatoma predictive of outcome? Cancer 2000;88: 538-543. doi: 10.1002/(SICI) 1097-0142(20000201)88:3<538::AID CNCR7>3.0.CO;2-H

[35] Marsh JW, Dvorchik I. Liver organ allocation for hepatocellular carcinoma: are we sure? Liver Transpl 2003;9:693-696. doi: 10.1053/jlts.2003.50086

[36] Mazzaferro V, Llovet JM, Miceli R, Bhoori S, Schiavo M, Mariani L, Camerini T, et al. Predicting survival after liver transplantation in patients with hepatocellular carcinoma beyond the Milan criteria: a retrospective, exploratory analysis. Lancet Oncol 2009;10:35-43. doi: 10.1016/S14702045(08)70284-5.

[37] Prasad KR, Young RS, Burra P, Zheng SS, Mazzaferro V, Moon DB, et al. Summary of candidate selection and expanded criteria for liver transplantation for hepatocellular carcinoma: a review and consensus statement. Live Transpl 2011;17 (Suppl 2):S81-89. doi: 10.1002/It.22380.

[38] Yao FY, Ferrell L, Bass NM, Watson J], Bacchetti P, Venook A, et al. Liver transplantation for hepatocellular carcinoma: expansion of the tumor size limits does not adversely impact survival. Hepatology 2001;33:1394-1403. doi: 10.1053/jhep.2001.24563

[39] Yao FY, Xiao L, Bass NM, Kerlan R, Ascher NL, Roberts JP. Liver transplantation for hepatocellular carcinoma: validation of the UCSF-expanded criteria based on preoperative imaging. Am J Transplant 2007;7:2587-2596. doi: 10.1111/j.1600-6143.2007.01965.x.

[40] Raj A, McCall J, Gane E. Validation of the "Metroticket" predictor in a cohort of patients transplanted for predominantly HBV-related hepatocellular carcinoma. J Hepatol 2011;55:1063-1068. doi: 10.1016/j.jhep.2011.01.052.

[41] Yao FY, Breitenstein S, Broelsch CE, Dufour JF, Sherman M. Does a patient qualify for liver transplantation after the down-staging of hepatocellular carcinoma? Liver Transpl 2011;17 (Suppl 2):S109-116. doi: 10.1002/ It. 22335.

[42] Pomfret EA, Washburn K, Wald C, Nalesnik MA, Douglas D, Russo M, et al. Report of a national conference on liver allocation in patients with hepatocellular carcinoma in the United States. Liver Transpl 2010;16:262278. doi: $10.1002 /$ It.21999.

[43] Mazzaferro V, Battiston C, Perrone S, Pulvirenti A, Regalia E, Romito R, et al. Radiofrequency ablation of small hepatocellular carcinoma in cirrhotic patients awaiting liver transplantation: a prospective study. Ann Surg 2004;240:900-909. doi: 10.1097/01.sla.0000143301.56154.95

[44] Lu DS, Yu NC, Raman SS, Lassman C, Tong MJ, Britten C, et al. Percutaneous radiofrequency ablation of hepatocellular carcinoma as a bridge to liver transplantation. Hepatology 2005;41:1130-1137. doi: 10.1002/hep.20688. 
[45] Majno PE, Adam R, Bismuth $\mathrm{H}$, Castaing D, Ariche A, Krissat J, et al. Influence of preoperative transarterial lipiodol chemoembolization on resection and transplantation for hepatocellular carcinoma in patients with cirrhosis. Ann Surg 1997;226:688-701; discussion 701-703. doi: 10.1097/00000658199712000-00006

[46] Decaens T, Roudot-Thoraval F, Bresson-Hadni S, Meyer C, Gugenheim J, Durand $F$, et al. Impact of pretransplantation transarterial chemoembolization on survival and recurrence after liver transplantation for hepatocellular carcinoma. Liver Transpl 2005;11:767-775. doi: 10.1002/It.20418

[47] Porrett PM, Peterman H, Rosen M, Sonnad S, Soulen M, Markmann JF, et al. Lack of benefit of pre-transplant locoregional hepatic therapy for hepatocellular cancer in the current MELD era. Liver Transpl 2006;12:665-673. doi: $10.1002 /$ It. 20636

[48] Llovet JM, Mas X, Aponte J], Fuster J, Navasa M, Christensen E, et al. Cost effectiveness of adjuvant therapy for hepatocellular carcinoma during the waiting list for liver transplantation. Gut 2002;50:123-128. doi: 10.1136/ gut.50.1.123

[49] Mazzaferro V, Majno P. Principles for the best multidisciplinary meetings. Lancet Oncol 2011;12:323-325. doi: 10.1016/S1470-2045(11)70010-9.

[50] Yao FY, Kerlan RK, Hirose R, Davern T], Bass NM, Feng S, et al. Excellent outcome following down-staging of hepatocellular carcinoma prior to liver transplantation: an intention-to-treat analysis. Hepatology 2008;48:819827. doi: 10.1002/hep.22412.

[51] Ravaioli M, Grazi GL, Piscaglia F, Trevisani F, Cescon M, Ercolani G, et al. Liver transplantation for hepatocellular carcinoma: results of down-staging in patients initially outside the Milan selection criteria. Am J Transplant 2008;8: 2547-2557. doi: 10.1111/j.1600-6143.2008.02409.x.

[52] De Carlis L, Di Sandro S, Giacomoni A, Slim A, Lauterio A, Mangoni I, et al. Beyond the Milan criteria: what risks for patients with hepatocellular carcinoma progression before liver transplantation? J Clin Gastroentero 2012;46:78-86. doi: 10.1097/MCG.0b013e31822b36f6

[53] Mela M, Mancuso A, Burroughs AK. Review article: hepatocellular carcinoma: indications for liver transplantation. Aliment Pharmacol Ther 2003;17 (Suppl 2):130-137. doi: 10.1046/j.1365-2036.17.s2.16.x.

[54] Duvoux C, Roudot-Thoraval F, Decaens T, Pessione F, Badran H, Piardi T, et al. Liver transplantation for hepatocellular carcinoma: a model including alphafetoprotein improves the performance of Milan criteria. Gastroenterology 2012;143:986-994 e983; quiz e914-985. doi: 10.1053/j.gas tro.2012.05.052.

[55] Trotter JF, Wachs M, Everson GT, Kam I. Adult-to-adult transplantation of the right hepatic lobe from a living donor. N Engl J Med 2002;346:1074-1082.

[56] Clavien PA, Petrowsky H, DeOliveira ML, Graf R. Strategies for safer liver surgery and partial liver transplantation. N Engl J Med 2007;356:15451559.

[57] Bruix J, Llovet JM. Prognostic prediction and treatment strategy in hepatocellular carcinoma. Hepatology 2002;35:519-524. doi: 10.1053/ jhep.2002.32089.

[58] Siegler M, Simmerling MC, Siegler JH, Cronin 2nd DC. Recipient deaths during donor surgery: a new ethical problem in living donor liver transplantation (LDLT). Liver Transpl 2006;12:358-360. doi: 10.1002/It.20670.

[59] Ghobrial RM, Freise CE, Trotter JF, Tong L, Ojo AO, Fair JH, et al. Donor morbidity after living donation for liver transplantation. Gastroenterology 2008;135:468-476. doi: 10.1053/j.gastro.2008.04.018.

[60] Browns Jr RS. Live donors in liver transplantation. Gastroenterology 2008; 134:1802-1813. doi: 10.1053/j.gastro.2008.02.092.

[61] Lo CM, Fan ST, Liu CL, Chan SC, Ng IO, Wong J. Living donor versus deceased donor liver transplantation for early irresectable hepatocellular carcinoma. Br J Surg 2007;94:78-86.

[62] Fisher RA, Kulik LM, Freise CE, Lok AS, Shearon TH, Brown Jr RS, et al. A2ALL Study Group. Hepatocellular carcinoma recurrence and death following living and deceased donor liver transplantation. Am J Transplant 2007;7:16011608.

[63] Sarasin FP, Majno PE, Llovet JM, Bruix J, Mentha G, Hadengue A. Living donor liver transplantation for early hepatocellular carcinoma: a lifeexpectancy and cost-effectiveness perspective. Hepatology 2001;33:1073-1079.

[64] Llovet JM, Ricci S, Mazzaferro V, Hilgard P, Gane E, Blanc JF, et al. SHARP Investigators Study Group. Sorafenib in advanced hepatocellular carcinoma. N Engl J Med 2008;359:378-390.

[65] Cheng AL, Kang YK, Chen Z, Tsao CJ, Qin S, Kim JS, et al. Efficacy and safety of sorafenib in patients in the Asia-Pacific region with advanced hepatocelIular carcinoma: a phase III randomised, double-blind, placebo-controlled trial. Lancet Oncol 2009;10:25-34. doi: 10.1016/S1470-2045(08)70285-7.

[66] Pfeiffenberger J, Koschny R, Hoffmann K, Mehrabi A, Schmitz A, Radeleff B, et al. Sorafenib treatment is save and may affect survival of recurrent hepatocellular carcinoma after liver transplantation. Langenbecks Arch Surg 2013;398:1123-1128. doi: 10.1007/s00423-013-1114-1.

[67] Waghray A, Balci B, El-Gazzaz G, Kim R, Pelley R, Narayanan Menon KV, et al. Safety and efficacy of sorafenib for the treatment of recurrent hepatocellular carcinoma after liver transplantation. Clin Transplant 2013:27:555-561. doi: $10.1111 /$ ctr.12150

[68] Sposito C, Mariani L, Germini A, Flores Reyes M, Bongini M, Grossi G, et al. Comparative efficacy of sorafenib versus best supportive care in recurrent hepatocellular carcinoma after liver transplantation: a case-control study. J Hepatol 2013;59:59-66. doi: 10.1016/j.jhep.2013.02.026.

[69] Sotiropoulos GC, Nowak KW, Fouzas I, Vernadakis S, Kykalos S, Klein CG et al. Sorafenib treatment for recurrent hepatocellular carcinoma after liver transplantation. Transplant Proc 2012;44:2754-2756. doi: 10.1016/j.transproceed.2012.09.022.

[70] Zavaglia C, Airoldi A, Mancuso A, Vangeli M, Viganò R, Cordone G, et al. Adverse events affect sorafenib efficacy in patients with recurrent hepatocellular carcinoma after liver transplantation: experience at a single center and review of the literature. Eur J Gastroenterol Hepatol 2013;25:180-186.

[71] Vitale A, Boccagni P, Kertusha X, Zanus G, D'Amico F, Lodo E, et al. Sorafenib for the treatment of recurrent hepatocellular carcinoma after liver transplantation? Transplant Proc 2012;44:1989-91. doi: 10.1016/j.transproceed.2012.06.046.

[72] Staufer K, Fischer L, Seegers B, Vettorazzi E, Nashan B, Sterneck M. High toxicity of sorafenib for recurrent hepatocellular carcinoma after liver transplantation. Transpl Int 2012;25:1158-64. doi: $10.1111 /$ j.1432 2277.2012.01540.x.

[73] Weinmann A, Niederle IM, Koch S, Hoppe-Lotichius M, Heise M, Düber C, et al. Sorafenib for recurrence of hepatocellular carcinoma after liver transplantation. Dig Liver Dis 2012;44:432-437. doi: 10.1016/j.dld.2011.12.009.

[74] Pfiffer TE, Seehofer D, Nicolaou A, Neuhaus R, Riess H, Trappe RU. Recurrent hepatocellular carcinoma in liver transplant recipients: parameters affecting time to recurrence, treatment options and survival in the sorafenib era. Tumori 2011;97:436-441. doi: 10.1700/950.10394.

[75] Gomez-Martin C, Bustamante J, Castroagudin JF, Salcedo M, Garralda E, Testillano $\mathrm{M}$, et al. Efficacy and safety of sorafenib in combination with mammalian target of rapamycin inhibitors for recurrent hepatocellular carcinoma after liver transplantation. Liver Transpl 2012;18:45-52. doi: $10.1002 /$ It. 22434.

[76] Tan WF, Qiu ZQ, YU Y, Ran RZ, Yi B, Lau WY, et al. Sorafenib extends the survival time of patients with multiple recurrences of hepatocellular carcinoma after liver transplantation. Acta Pharmacol Sin 2010;31:16431648. doi: 10.1038/aps.2010.124.

[77] Kim R, El-Gazzaz G, Tan A, Elson P, Byrne M, Chang YD, et al. Safety and feasibility of using sorafenib in recurrent hepatocellular carcinoma after orthotopic liver transplantation. Oncology 2010;79:62-66. doi: 10.1159/ 000319548.

[78] Yoon DH, Ryoo BY, Ryu MH, Lee SG, Hwang S, Suh DJ, et al. Jpn Sorafenib for recurrent hepatocellular carcinoma after liver transplantation. J Clin Oncol 2010;40:768-773. doi: 10.1093/jjco/hyq055.

[79] Valdivieso A, Bustamante J, Gastaca M, Uriarte JG, Ventoso A, Ruiz P, et al. Management of hepatocellular carcinoma recurrence after liver transplantation. Transplant Proc 2010;42:660-662. doi: 10.1016/j.transproceed.2010.02.014.

[80] Feun LG, Levi D, Moon J, Nishida S, Island E, Selvaggi G, et al. Sorafenib in hepatocellular carcinoma (HCC) patients after liver transplantation. J Clin Oncol 2009;27 (suppl 20):e15579.

[81] Derancy S, Romano O., Lorho R., et al. Tolerability and efficacy ofsorafennib in recurrent hepatocellularcarcinoma after livertransplantation: a casecontrol study. Abstract book EASL 2010

[82] Toso C, Mentha G, Majno P. Integrating sorafenib into an algorithm for the management of post-transplant hepatocellular carcinoma recurrence. J Hepatol 2013;59:3-5. doi: 10.1016/j.jhep.2013.03.029.

[83] Mancuso A, Mazzarelli C, Perricone G, Zavaglia C. Sorafenib efficacy for treatment of HCC recurrence after Liver Transplantation is an open issue. J Hepatol 2014;60:681. doi: 10.1016/j.jhep.2013.10.030

[84] Sposito C, Mazzaferro V. Reply to "Sorafenib efficacy for treatment of HCC recurrence after Liver Transplantation is an open issue". J Hepatol 2014;60: 682-683. doi: 10.1016/j.jhep.2013.10.032

[85] Mancuso A, Airoldi A, Vigano R, Pinzello G. Fatal gastric bleeding during sorafenib treatment for hepatocellular carcinoma recurrence after liver transplantation. Dig Liver Dis 2011;43:754. doi: 10.1016/j.dld.2011.04.022.

[86] Mancuso, Zavaglia C, Bai F, Puoti M, Belli L. Sorafenib hepatotoxicity seems to be enhanced by HAARTS interaction during treatment of advanced hepatocelluler carcinoma in HIV-infected patients. Aliment Pharmacol Ther 2013;38:1414-1416. doi: 10.1111/apt.12536. 